\title{
The Hammock as a Therapeutic Alternative at The Neonatal Intensive Care Unit
}

\author{
Silvana Alves Pereira', Gentil Gomes da Fonseca Filho', Norrara Scarlytt de Oliveira Holanda², \\ Daniela Elizabeth de Castro Vieira ${ }^{3}$, Cristiane Aparecida Moran ${ }^{4}$
}

\begin{abstract}
Background: Among the therapeutic alternatives complementary to humanized care, there is the vestibular stimulation. Provided by the gentle swing in a hammock, it simulates the containment and maternal movements found in the intrauterine environment and is considered a safe method that reduces stress levels in very low birthweight premature newborn (PTNB). Objective: To observe the time of hospitalization and the discharge weight of the PTNB that passed through the positioning in the hammock and kangaroo mother care. Methods: A quasi-experimental study involving two university hospitals including PTNB. The PTNB were allocated into two groups: Kangaroo Mother Care (KMC) composed by PTNB selected according to the maternal presence and vestibular stimulation (VS) composed by PTNB whose maternal presence was not possible. The KMC were kept in skin-to-skin contact with the mother. The VS were positioned in dorsal decubitus in a hammock of cotton adapted within the incubator. The time of hospitalization and weight monitoring were recorded daily by the nursing team in a collection form. Results: From the 40 PTNB included in this study, $47.5 \%$ were female and $40 \%$ had normal birth, 20 of them were allocated in the VS group and 20 in the KMC group. The time of hospitalization were not different between the groups ( $p=0.12)$, but the discharge weight were higher in the VS group $(p<0.05)$. Conclusion: The data indicate that the hospitalization time is similar between the PTNB who received KMC and VS, and that the discharge weight is higher for the group that received the VS.
\end{abstract}

Keywords: Newborn; Preterm Newborn; Position Modes; Child Development.

\section{INTRODUCTION}

In Brazil, approximately $9.2 \%$ of newborns (NB) are premature, classified according to the moment of birth that occurs before 37 weeks of gestational age ${ }^{(1)}$. It is estimated that in hospitals that provide care for high-risk pregnancies, such as the 'Hospital São Paulo', linked to the 'Federal University of São Paulo', there is an incidence of about 20\% of severe cases, with a probability of $8 \%$ of death in the first year of life in the entire state of São Paulo(3). The preterm newborn (PTNB) need extreme care in the Neonatal Intensive Care Unit (NICU), because early childbirth is considered an aggression to the body in several senses, whose maturation process of the systems is under development ${ }^{(4)}$. PTNB suffers from prematurity of organs and systems and is subjected to numerous negative effects of hospitalization, such as frequent handling for exams and procedures that almost always interrupt the sleep-wake of the newborn, generating a high stress index ${ }^{(5)}$. The Brazilian Ministry of Health has proposed actions such as the Kangaroo Mother Care (KMC), as a National Health Policy, with the aim of humanizing the care of
PTNB $^{(6)}$. The regulation of Humanized Attention to Low Weight Newborns by the KMC was released in December, $1999^{(7)}$. This strategy aims to reconcile the best available treatment methods with respect to individualities, allowing security and ensuring the reception of the NB and his family, based on the humanized practice ${ }^{(6,7)}$. KMC is a technique that allows skinto-skin contact between mother and newborn. This method increases the bond between them ${ }^{(8)}$, improves the quality of development of the PTNB ${ }^{(8)}$ for weight gain and reduced stress and pain ${ }^{(9)}$, making the stay at the NICU less inhospitable and reducing hospitalization time ${ }^{(10)}$. Among the therapeutic alternatives complementary to humanized care, there is the vestibular stimulation (VS) ${ }^{(11)}$. It is provided by the gentle balance in a hammock, that simulates the containment and maternal movements found in the intrauterine environment ${ }^{(12)}$, and can be considered a safe method, which reduces stress levels and energy expenditure in very low weight PTNB ${ }^{(13 .)}$ Its ordination is characterized by the formation of a rectangle tissue suspended at both ends for the accommodation of the

Corresponding Author: Cristiane Aparecida Moran. Address: Universidade Federal de Santa Catarina. Department of Health Sciences - Campus Jardim das Avenidas - Rodovia Governador Jorge Lacerda, 3201 - Jardim das Avenidas - CEP 88900-000. Araranguá - Santa Catarina - Brazil. Tel.: +55 48 99664-7756. E-mail: cristiane.moran@ufsc.br

${ }^{4}$ Universidade Federal de Santa Catarina - UFSC - Araranguá (SC), Brasil

Full list of author information is available at the end of the article.

Financial support: The authors declare that there was no financial support.

Submission date 11 Outubro 2018; Acceptance date 26 November 2018; Publication date 14 December 2018 
$\mathrm{NB}^{(14)}$. This condition provides a central alignment of the upper and lower limbs and the NB head from the flexor position, allowing a stability of the respiratory system, neuromotor and cognitive systematization, facilitates feeding, as well as improving behavior, interaction with the environment and general properties of child growth and development, such as oral-neuromotor, visual and auditory abilities ${ }^{(13)}$. In this perspective, the hammock position is considered an important method for particular cases of maternal absence, since it favors humanized reception based on the simulation of some characteristics of the intrauterine environment that contribute to the acquisition and development of neuromotor frames ${ }^{(14)}$. With the hypothesis of assessing if the effects of SV are similar to KMC, allowing the indication of SV in the NICU, the objective of the study was to observe the length of hospital stay and the discharge weight of the PTNB that passed through the SV or KMC.

\section{METHODS}

\section{STUDY DESIGN, SUBJECTS AND ETHICAL CONSIDERATION}

This is a quasi-experimental study, with a sample for convenience, involving NICU of two university hospitals located in the Southeast and Northeast of Brazil. The PTNB with a gestational age of 31 to 36 weeks, from the 5th day of life, with hemodynamic stability, Apgar Score in 1' and 5' above 7 points and current minimum weight of 1100 grams were included in the study, and were excluded the PTNB who had one or more of the following characteristics: cardiac or neurological diseases, osteopenia of prematurity, in invasive or non-invasive mechanical ventilation and who received anticonvulsant, sedative or analgesic medication at the time of the intervention. The PTNB were divided into two groups: The KMC group consisted of newborns selected according to the maternal presence in the NICU and the VS group composed of newborns whose maternal presence was not possible in the NICU. In the KMC group, the PTNB were kept in skin-to-skin contact with the mother, with little clothing as possible, and in the VS group the newborns were placed in dorsal decubitus in a cotton hammock adapted within the incubator or crib, in a smooth balance promoted by the body movement of the newborn. KMC or VS positions were once daily with a 2-hour stay until ICU discharge. The time of hospitalization and weight monitoring were recorded in a data collection form according to the daily measurement performed by the nursing team. The researchers who conducted the research were trained and supervised by the responsible teacher, and the parents authorized the participation of their children by signing the informed consent form. The present research was approved by the Ethics and Research Committee, protocol number 1527741360005511.

\section{STATISTICAL ANALYSIS}

To analyze the data, descriptive analyzes were performed by calculation of means and standard deviations. The normality of the distribution was performed with the Kolmogorov-Smirnov test. To compare the Time of Hospitalization and Discharge Weight variables between groups, was used the Mann-Whitney U test. For the correlation analysis, was used the Spearman's correlation coefficient.

\section{RESULTS}

From the 40 PTNB included in this study, $47.5 \%$ were female and $40 \%$ had normal birth, 20 of them were allocated in the VS group and 20 in the KMC group. Table 1 shows the characterization of the sample.

Although the time of hospitalization was lower for the KMC group ( 22 days \pm 8 ) compared to SV (29 days \pm 16 ), the difference was not significant $(U=143.00 ; p=0.12)$, however, the discharge weight was significantly higher for the VS group compared to KMC $(U=123.00 ; p<0.05)$. Table 2 shows the stratification of these results.

In the analysis of correlations, there were positive correlations between the Discharge Weight and Gestational Age variables $(\rho=0.48 ; p<0.01)$, Birth Weight and Discharge Weight $(\rho=0.87 ; p<0.01)$ and negative correlations between Time of Hospitalization and Discharge Weight $(\rho=-0.49 ; p<0.01)$, Time of Hospitalization and Birth Weight $(\rho=-0.63 ; p<0.01)$, and Time of Hospitalization and Gestational Age $(\rho=-0.54 ; p<0.01)$.

Table 1 - Characterization of the sample

\begin{tabular}{|c|c|c|c|c|c|}
\hline & & \multicolumn{2}{|c|}{ VS } & \multicolumn{2}{|c|}{ KMC } \\
\hline & & $\mathbf{N}$ & $\%$ & $\mathbf{N}$ & $\%$ \\
\hline \multirow{2}{*}{ Gender } & Female & 9 & $45.0 \%$ & 10 & $50.0 \%$ \\
\hline & Male & 11 & $55.0 \%$ & 10 & $50.0 \%$ \\
\hline \multirow{2}{*}{ Birth } & Cesarean & 13 & $65.0 \%$ & 11 & $55.0 \%$ \\
\hline & Normal & 7 & $35.0 \%$ & 9 & $45.0 \%$ \\
\hline
\end{tabular}

Note: VS=Vestibular Stimulation; KMC=Kangaroo Mother Care.

Table 2 - Mean and Standard Deviation (SD) of the quantitative variables.

\begin{tabular}{|c|c|c|c|}
\hline \multirow{2}{*}{ Variables } & VS & KMC & \multirow{2}{*}{$\mathrm{U}$ test } \\
\hline & Mean (SD) & Mean (SD) & \\
\hline Gestational Age & $33(2)$ & $33(2)$ & Not significant \\
\hline Birth Weight & $1678(372)$ & 1825 (262) & Not significant \\
\hline Mother's age & $24(9)$ & $28(6)$ & Not significant \\
\hline Discharge Weight & 2038 (209) & $1878(242)$ & $p<0.05^{*}$ \\
\hline $\begin{array}{l}\text { Time of } \\
\text { Hospitalization }\end{array}$ & $29(16)$ & $22(8)$ & Not significant \\
\hline Days of Life & $9(4)$ & $6(1)$ & $p<0.05^{*}$ \\
\hline
\end{tabular}

Note: VS=Vestibular Stimulation; KMC=Kangaroo Mother Care. 


\section{DISCUSSION}

These results demonstrate that hospitalization time is similar between the PTNB who received KMC and VS, and that the discharge weight of the newborn is higher for the group that received vestibular stimulation. The PTNB admitted at the NICU are often submitted to invasive procedures that, while important, may impair their development ${ }^{(15)}$, such as noise and handling for testing, causing energy expenditure and slowing the weight gain ${ }^{(16)}$. In this context, another factor that can delay weight gain and consequently increase hospitalization time, is the difficulty of the NB in maintaining body temperature, requiring greater consumption of oxygen and energy for heat production ${ }^{(17)}$. In addition to the KMC proposed by the Ministry of Health as a way to humanize care in the $\operatorname{NICU}^{(6,18)}$, there is also the vestibular stimulation, a technique that aims to reduce the negative effects of hospitalization, providing the conditions similar to those of the maternal uterus ${ }^{(12)}$. A decrease in state disorganization, behavioral improvement and weight gain seems to be beneficial in the application of vestibular stimulation in newborns ${ }^{(19,20)}$. The KMC, already consolidated in the literature, provides innumerable benefits to the PTNB. The main contribution is regarding weight gain, which consists of an important variable in the assessment of the development of the neonate ${ }^{(21)}$. This method allows the NB to be breastfed early, which reduces weight loss due to the great nutritional benefit that breast milk provides ${ }^{(22,23)}$. In addition, KMC assists in the thermoregulation control of the PTNB ${ }^{(24)}$ and decreases the levels of stress causing that there is less energetic expenditure ${ }^{(25)}$. According to data from a research carried out in a maternity hospital in the city of São Paulo, Brazil, from 2002 to 2004, the mean of daily weight gain of PTNB submitted to KMC was $15.8 \mathrm{~g} /$ day, compared to those who did not participate in the method, who had a mean weight gain of $14.9 \mathrm{~g} /$ day. Regarding the time of hospitalization of the PTNB at the ICU, it was observed a stay of $27.3 \pm 8.4 /$ days for the $\mathrm{KMC}$ and $26.2 \pm 12.5 /$ days for the ones who did not performed the $\operatorname{method}^{(26)}$.

In a randomized study, Keller et al., (2003) observed the neurobehavioral and autonomic effects of the hammock positioning in very low birth weight infants ${ }^{(34)}$. A total of 20 babies with weight $<1.500 \mathrm{~g}$ were included in the study, randomized into two groups, in which they were paired according to gestational age, postnatal age and weight. A total of ten newborns were conditioned to supine position in a hammock for three hours daily for ten consecutive days, and ten newborns were kept nested in ventral decubitus, following the same application time of the previous group. As results, the researchers observed that the supine position in the hammock presented a higher score of neuromuscular maturity ( $p<0.003$ ), in addition to exposing better relaxation condition, lower heart rate and respiratory rate ( $p<0.05$ and $p<0.01$, respectively), positively influencing the autonomic stability and the neuromuscular maturity ${ }^{(34)}$.
In our study it was possible to observe a greater weight at hospital discharge in the VS group when compared to the KMC group. This finding can be understood through the state of relaxation provided by the "simulation" of the intrauterine environment performed by the newborn movements in the hammock, reducing irritability, besides providing reduction of heat loss and lower energy reserve expenditure, which contribute to the increase in weight ${ }^{(35)}$.

In this perspective, VS is a method in which the PTNB's are positioned in a hammock adapted within the incubator or crib with a gentle balance promoted by the own body movement of the NB. The hammock simulates the maternal uterus and allows PTNB to have similar benefits to what it would have in the uterine environment ${ }^{(27)}$ such as decreased irritability and a longer stay in quiet sleep, promoting the preservation of the physiological reserves of the newborn, stimulating the postural organization and activating areas of the brain involved in the perception of the body in space ${ }^{(19,28,29)}$. VS presented benefits similar to KMC, thus the newborns who do not have the mother's presence in the ICU can undergo vestibular stimulation and obtain the same benefits. Thus, it is important to highlight that, as observed in our study, the hammock position has a substantial contribution in the hospital practice in order to contribute to the harmony of the movements of the NB members and reduction of energy expenditure ${ }^{(36)}$. This positioning provides a reduction of stress, better tonic and behavioral reorganization, weight gain and better comfort, being these determinants for the best neuropsychomotor development of the preterm baby ${ }^{(36)}$. The newborns considered at term have as dominant position the flexion of the extremities and a flexor tone (physiological) that indicates the maturation of the central nervous system ${ }^{(30)}$. The PTNB does not present this neurological maturity, impairing the development of the physiological tone and causing them to present a hypotony ${ }^{(30)}$. Hypotony, in this case, shows that the central nervous system of the newborn is not completely ready for extra-uterine life and this may delay their development ${ }^{(19,31,15)}$. The positioning in the hammock due to its fixation in the incubator promotes restraint and flexural posture, movement control and midline orientation. Therefore, it can be suggest that VS potentiates the flexor tone by simulating the maternal uterus, promoting stimuli that minimize the damages of early birth, contributing to weight gain, development and decreasing the hospitalization time $^{(32,33)}$. The weight gain for the VS group is considered the greatest finding of our study, besides being observed, according to the literature, that the use of the position of the hammock is favorable because it presents positive results in short term for the development of the newborn. However, the technique using the hammock for the newborns still lacks parameters to use in institutions ${ }^{(36)}$. Thus, it is important to improve scientific research in this expanding field. 


\section{CONCLUSION}

The data indicate that the hospitalization time is similar between the PTNB who received KMC and VS, and that the discharge weight is higher for the group that received the VS.

\section{AUTHORS' CONTRIBUTIONS}

SA and CA were responsible for study ideation and design of the work; GG was responsible for statistical analysis; NS and CA wrote the initial version of the paper; NS and DE reviewed and contributed to the writing of the final version of the paper. NS and DE participated in the collection of data. All the authors read and approved the final version of the manuscript.

\section{CONFLICT OF INTERESTS}

The authors declare that there was no conflict of interests.

\section{AUTHORS DETAILS}

${ }^{1}$ Universidade Federal do Rio Grande do Norte - UFRN - Natal (RN), Brazil. ${ }^{2}$ Faculdade de Ciências da Saúde do Trairi - FACISA - Universidade Federal do Rio Grande do Norte - UFRN - Natal (RN), Brasil. ${ }^{3}$ Conjunto Hospitalar do Mandaqui, São Paulo (SP), Brasil

\section{REFERENCES}

1. Silveira MF, Matijasevich A, Horta BL, Bettiol H, Barbieril MA, Silva AA, et al. Prevalência de nascimentos pré-termo por peso ao nascer: revisão sistemática. Rev Saúde Pública. 2013; 47: 992-1000.

2. Rabello MSC, Barros SMO. Aspectos clínicos e epidemiológicos da prematuridade em um Centro de Parto Normal, São Paulo, Brasil. Einstein. 2011; 9: 483-8.

3. Colameo AJ, Rea MF. O Método Mãe Canguru em hospitais públicos do Estado de São Paulo, Brasil: uma análise do processo de implantação. Cad Saúde Pública. 2006; 22: 597-607.

4. Sousa DS, Sousa Júnior AS, Santos ADR, Melo EV, Lima SO, Almeida-Santos $M A$, et al. Morbidade em recém- nascidos prematuros de extremo baixo peso em unidade de terapia intensiva neonatal. Rev Bras Saúde Matern Infant. 2017; 17: 149-157.

5. Toso BRGO, Viera CS, Valter JM, Delatore S, Barreto GMS. Validação de protocolo de posicionamento de recém-nascido em Unidade de Terapia Intensiva. Rev Bras Enferm. 2015; 68: 1147-53.

6. Chagas DO, Pereira MAS, Nicomedes TM, Lima RABC, Azevedo VMGO, Gontijo FO. Comparison of maternal adhesion to the guidelines for the method of Kangaroo Mother in pre-and post-discharge from Hospital Sofia Feldman. Rev Med Minas Gerais. 2011; 21: 5-8.

7. Maia JA, Oliveira MP, Furtado SS, Silva LM, Pereira MLB. Método Canguru: a importância da família na recuperação do recém-nascido de baixo peso. Enfermagem em Foco. 2011; 2: 231-234.

8. Santos MH, Filho FMA. Benefits of the mother kangaroo method in newborn pre-term or weight down: a review of the literature. Ciências da Saúde. 2016; 14: 67-76.

9. Azevedo VMGO, Bernardes David R, Coelho Xavier C. Kangaroo mother care in preterm newborns on artificial ventilation: an evaluation of behavior patterns. Rev Bras Saúde Matern. Infant. 2011; 11: 133-138.

10. Gao H, Xu G, Gao H, Dong R, Fu H, Wang D, et al. Effect of repeated Kangaroo Mother Care on repeated procedural pain in preterm infants: A randomized controlled trial. Int J Nurs Stud. 2015; 52: 1157-65.

11. Nascimento Nunesa CR, Campos LG, Lucena AM, Pereira JM, Costa PR, Lima FAF, et al. Relationship between the use of kangaroo position on preterm babies and mother-child interaction upon discharge. Rev Paul Pediatr. 2017; 35: 136-143.

12. Burns K, Cunningham N, White-Traut R, et al. Infant stimulation: modification of an intervention based on physiologic and behavioral cues. J Obstet Gynecol Neonatal Nurs. 1994; 23: 581-9.
13. Bezerra IFD, Torres VB, Lopes JM, Baroni MP, Pereira SP. Assessment of the influence of the hammock on neuromotor development in nursing full-term infants. Journal of Human Growth and Development. 2014; 24: 106-111.

14. Costa KSF, Beleza LO, Souza LM, Ribeiro LM. Hammock position and nesting: comparison of physiological and behavioral effects in preterm infants. Rev Gaúcha Enferm. 2016; 37: 1-9.

15. Gitto E, Pellegrino S, Manfrida M, Aversa S, Trimarchi G, Barberi I, et al. Stress responce and procedural pain in the preterm newborn: the role of pharmalogical and non- pharmalogical treatments. Eur J Pediatr. 2012; 171 : 927-33.

16. Cardoso SMS, Kozlowski LC, Lacerda ABM, Marques JM, Ribas A. Newborn physiological responses to noise in the neonatal unit. Braz J Otorhinolaryngol. 2015; 81: 583-588.

17. Davanzo R. Newborns in adverse conditions: issues, challenges, and interventions. J Midwifery Womens Health 2004; 49 (4 Suppl 1): 29-35.

18. Nunes CRN, Campos LG, Lucena AM, Pereira JM, Costa PR, Lima FAF, et al. Relationship between the use of kangaroo position on preterm babies and mother-child interaction upon discharge. Rev Paul Pediatr. 2017; 35: 136143.

19. Dieter JN, Emory EK. Supplemental stimulation of premature infants: a treatment model. J Pediatr Psychol. 1997; 22: 281-95.

20. White-Traut RC, Nelson MN, Silvestri JM, Cunningham N, Patel M. Responses of preterm infants to unimodal and multimodal sensory intervention. Pediatr Nurs. 1997; 23:169-75.

21. Souza AKCM, Tavares ACM, Carvalho DGL, Araújo VC. Weight gain in newborns submitted to skin-to-skin contact. Rev CEFAC. 2018; 20: 53-60.

22. Bitman J, Wood L, Hamosh M, Hamosh P, Mehta NR. Comparison of the lipid composition of breast milk from mothers of term and preterm infants. Am J Clin Nutr. 1983; 38: 300-12.

23. Janas LM, Picciano MF. Quantities of amino acids ingested by human milk - fed infants. J Pediatr. 1986; 109: 802-7.

24. Casati PS, Oliveira CB, Paula S. Kangaroo mother care and its association with benefits of low weight newbo. UNICiências. 2010; 14: 135-146.

25. Lino LH, Coelho PG, Fonseca FLA, Filipini R. The swing balance benefits in incubators with newborns on neonatal ICU: the humanization strategy. Rev Enfermagem Revista. 2015; 18: 88-100.

26. Rodrigues MAG, Cano MAT. Estudo do ganho de peso e duração da internação do recém-nascido pré-termo de baixo peso com a utilização do método canguru. Rev eletrônica enferm. 2006; 8: 185-91.

27. Jesus VR, Oliveira PMN, Azevedo VMGO. Effects of hammock positioning in behavioral status, vital signs, and pain in preterms: a case series study. Brazilian journal of physical therapy. Braz J Phys Ther. 2018; 22: 304-309.

28. Dorrn AL, Yuan K, Barker AJ, Schreiner CE, Froemke RC. Developmental sensory experience balances cortical excitation and inhibition. Nature international juornal of science. 2010; 465: 932-936.

29. Bottini G, Gandola M, Sedda A, Ferrè ER. Caloric vestibular stimulation: interaction between somatosensory system and vestibular apparatus. Front Integr Neurosci. 2013; 7: 66.

30. Vergara ER, Bigsby R. Developmental and Therapeutic Interventions in the NICU. Baltimore, MD: Paul H Brookes Publishing Company; 2004.

31. Sweeney JK, Gutierrez T. Musculoskeletal implications of preterm infant positioning in the NICU. J Perinat Neonatal Nurs. 2002; 16: 58-70.

32. Bauer K. Effects of positioning and handling on preterm infants in the neonatal intensive care unit, in Research on Early Developmental Care for Preterm Neonates. Paris: John Libbey Eurotext; 2005.

33. Rafaini PGC, Pacciulo AM, Panúncio-Pinto MP, Pfeiter LI. Estimulación Temprana em enfermería pediátrica: El papel Del terapeuta ocupacional. TOG (A Coruña). 2012; 9: 1-11.

34. Keller A, Arbel N, Merlob P, Davidson S. Neurobehavioral and autonomic effects of hammock positioning in infants with very low birth weight. Ped Phys Ther. 2003; 15: 3-7.

35. Ziade S, Toledo M, Rebelo C. No Embalo da Rede. Minas saúde. 2009; 2: 20-23.

36. Leone PS, Silva LJ, Porto FR, Santos IMM, Adegas ECV, Gomes TO. Uso da rede para posicionamento do prematuro na UTI neonatal: análise de notícias eletrônicas. J res fundam care online. 2018; 10: 106-112. 